\title{
Establishment of reverse transcription polymerase chain reaction assay for simultaneous detection of human parainfluenza virus types 1 to 4 in children with influenza like illnesses
}

\author{
GhelichKhan $\mathrm{M}^{1,2}$, Hosseini $\mathrm{SM}^{2}$, Khansarinejad B ${ }^{3}$, Fotouhi $\mathrm{F}^{2}$ \\ Department of Influenza and other Respiratory Viruses, Pasteur Institute of Iran, Tehran, Iran. \\ fotouhi@pasteur.ac.ir
}

\begin{abstract}
OBJECTIVES: The aim of this study was to develop an in-house multiplex reverse transcription polymerase chain reaction (mRT-PCR), which can recognize HPIV1-4 in clinical samples.

BACKGROUND: Human parainfluenza virus (HPIV) is one of the major causes of viral respiratory infections and can affect people at any age, especially infants and young children.

METHODS: Four sets of specific primers targeting conserved areas of hemagglutinin-neuraminidase (HN) genes of HPIV1-4, were designed and tested with type-related plasmid controls. Specificity and sensitivity of mPCR were tested. One-step mRT-PCR was set up using a viral panel containing 10 respiratory viruses, including HPIVs. One hundred nasopharyngeal samples of respiratory infection patients were tested using the set One-step mRT-PCR.

RESULTS: The specificity of set mPCR for HPIV1-4 using plasmid positive controls was proved and reaction sensitivity was measured. The specificity of set mRT-PCR was confirmed and 4 and 5 out of 100 clinical samples were HPIV1 and HPIV2 positive, respectively.

CONCLUSION: The developed one-step mRT-PCR in this study is an effective and specific assay for clinical diagnosis of HPIV1 to 4 (Tab. 1, Fig. 6, Ref. 28). Text in PDF www.elis.sk.

KEY WORDS: human parainfluenza virus, human, reverse transcriptase PCR, respiratory tract infections.
\end{abstract}

\section{Introduction}

Respiratory tract infections in infants and children 5 years old or younger are a major cause of morbidity and mortality. Viruses are considered the main reason for these infections. Human Parainfluenza viruses can infect persons at any age, but are the second-leading cause of respiratory illness hospitalizations in young children (1-3). HPIVs are enveloped, single stranded, nonsegmented negative sense RNA viruses that belong to Paramyxoviridae family and have four types based on genetic and antigenic characteristics and clinical presentation and differ in seasonality worldwide. HPIV types 1 and 3 belong to Respirovirus genus and types 2, and 4 belong to Rubulavirus genus (4-6).

The HPIVs can cause a wide spectrum of respiratory diseases in children, including rhinorrhea, cough, bronchiolitis, croup, and pneumonia. The majority of cases are mild upper respiratory tract

${ }^{1}$ Department of Microbiology, Faculty of Biological Sciences, Shahid Beheshti University, Tehran, Iran, ${ }^{2}$ Department of Influenza and other Respiratory Viruses, Pasteur Institute of Iran, Tehran, Iran, and ${ }^{3}$ Department of Microbiology and Immunology, Arak University of Medical Sciences, Arak, Iran

Address for correspondence: F. Fotouhi, PhD, Department of Influenza and other Respiratory Viruses, Pasteur Institute of Iran, No. 75, 12th Farvardin Ave, Jomhoori Street, 1316943551Tehran, Iran.

Phone: +9821.64112130, Fax: +9821.66496517 infections that can be asymptomatic, but in the immunocompromised host, HPIV infection can cause lower respiratory tract infections, become persistent, or the patient may develop secondary bacterial infection, which all have worse outcomes and can lead to death (7-10). Even though efforts have been made, currently no licensed specific antiviral therapy or vaccine is available against the HPIVs (11-14).

In past studies, several methods have been used to detect these viruses in patients with upper and lower respiratory tract diseases, which differ in expenses, sensitivity, specificity, ease of use and turnaround time. These methods include viral isolation, direct viral antigen detection, serological techniques, immunofluorescence or enzyme immunoassay and nucleic acid amplification methods like reverse transcription polymerase chain reaction (RT-PCR). Studies comparing these different methods seem to suggest that RT-PCR, considering reliability, specificity, speed, reproducibility of results and other aspects, is one of the best choices for this purpose at present and can be widely used in health care systems $(5,15,16)$.

In this study, we developed a one-step multiplex RT-PCR using type-specific primer pairs targeting the conserved regions of the HN gene of HPIV1-4 to detect any of four HPIV types in 100 inpatient respiratory samples with influenza-like illnesses' symptoms.

The purpose of the present study, considering the importance of accurate diagnosis in health care system's goal of lowering medical costs and preventing the unnecessary use of antibiotics, was to 
develop a one-step multiplex RT-PCR that is able to detect types 1-4 of HPIV in any one clinical respiratory sample.

\section{Materials and methods}

\section{Primer design}

The nucleotide sequences of all $\mathrm{HN}$ genes were obtained from the National Center for Biotechnology Information (NCBI) and aligned to find the most conserved regions. Using AlleleID software, four type-specific primer pairs were designed for a conserved region of the each HPIV HN gene. Thermodynamic characteristics and ability of the primers to function properly in a multiplex RTPCR were analyzed using Oligo6 and Oligo analyzer software. The designed primers were synthesized by Tag Copenhagen (Denmark). The Primers sequences are displayed in Table 1.

\section{Plasmid control}

In order to prepare a control template for PCR, complete HN gene of each human parainfluenza virus type ( 1 to 4 ) were synthesized and inserted into pBSK plasmid (pBluescript SK (+), BIOMAIK-Canada). Plasmids (lyophilized powder) were prepared as instructed by the manufacturer, and were introduced into E.coli TOP10 F' using thermal shock method. After 18 hours, the plasmids were extracted using YTA Plasmid DNA Extraction Mini Kit, and the concentration was determined by spectrophotometry at $260 \mathrm{~nm}$ and stored at $-20{ }^{\circ} \mathrm{C}$ for further use.

To evaluate primers accuracy and functionality, preliminary singleplex PCR assays were done using primers and related control template. Total volume of each reaction was $25 \mu 1$, containing $0.4 \mu \mathrm{M}$ of each primer and $1 \mathrm{ng}$ template. The thermal profile consisted of an initial step at $95^{\circ} \mathrm{C}$ for 10 minutes, 35 cycles of 15 seconds at $95^{\circ} \mathrm{C}, 20 \mathrm{sec}$ at $55^{\circ} \mathrm{C}$ and $40 \mathrm{sec}$ at $72{ }^{\circ} \mathrm{C}$, followed by the final extension at $72{ }^{\circ} \mathrm{C}$ for $10 \mathrm{~min}$. PCR products were evaluated using gel electrophoresis.

\section{PCR sensitivity}

In order to determine the test sensitivity, plasmids were linearized by ScaI enzyme (Jena Bioscience) as recommended by BioEdit and Snap Gene Viewer software. Serial dilutions $\left(10^{-1}\right.$ to $10^{-10} \mathrm{ng} /$ $\mathrm{mL}$ ) of linearized plasmids were entered as the template in a PCR test, and the minimum concentration, which resulted in a visible band in gel electrophoresis, was labeled as the detection limit of the test. The gene copy number can be calculated using the formula below. number of copies(molecules) $=$ (amount of amplicon(ng)* $\left.6.022 \times 10^{23}\right) /\left(\right.$ length of dsDNA amplicon * $1 \times 10^{9} * 650$ )

\section{PCR specificity}

To ensure the specificity of each primer, and to rule out possible cross reaction, each primer pair along with 3 other unrelated HPIV plasmids were entered in a PCR reaction.

\section{Multiplex PCR}

Multiplex PCR was accomplished to amplify HPIV1, HPIV2, HPIV3, and HPIV4 target sequence using specific primers in a single PCR reaction. The reaction was performed in a total volume of $25 \mu \mathrm{l}$, contained $0.4 \mu \mathrm{M}$ of each HPIV1-4 specific primers and 1ng of HPIV1-4 template plasmid.

\section{RT-PCR specificity}

In order to evaluate the specificity of designed primers for detection of viral RNA in clinical samples, a viral panel (Vircell - AMPLIRUN TOTAL RESPIRATORY VIRAL PANEL CONTROL (SWAB)) containing 10 respiratory viruses was used as the positive control in a multiplex RT-PCR test. The panel included inactivated adenovirus type 4, coronavirus, influenza A H1N1, A $\mathrm{H} 3$ and B viruses, HPIV types1, 2, and 3, and respiratory syncytial virus (subtypes A and B). The lyophilized panel was prepared as instructed by the company and the viral ribonucleic acids were extracted using High Pure Viral RNA Kit (ROCH- Switzerland).

Multiplex RT-PCR was done using designed primers and YTA (Yekta Tajhiz Azma) one step RT-PCR smart mix kit. The reaction was carried out in $25 \mu \mathrm{l}$ of reaction mixture consisting of $12.5 \mu \mathrm{l}$ one-step Multiplex master mix, $2 \mu 1$ of primer mix $(0.4 \mu \mathrm{M}$ of HPIV1-4 primers), and $10.5 \mu \mathrm{l}$ of template. Thermal profile of the RT-PCR consisted of an initial cDNA step of $30 \mathrm{~min}$ at $50{ }^{\circ} \mathrm{C}$ followed by $10 \mathrm{~min}$ at $95^{\circ} \mathrm{C}, 35$ cycles of $15 \mathrm{~s}$ at $95^{\circ} \mathrm{C}, 20 \mathrm{~s}$ at 55 ${ }^{\circ} \mathrm{C}, 40 \mathrm{~s}$ at $72{ }^{\circ} \mathrm{C}$ and a final extension at $72{ }^{\circ} \mathrm{C}$ for $10 \mathrm{~min}$. Each test contained negative and internal controls.

Application of multiplex RT-PCR to detect HPIVs in clinical samples

In this study, 100 nasopharyngeal swab samples from patients ( $\leq 5$ years of age) admitted to hospital for Influenza-like illness symptoms were chosen. Samples were collected from March 2013 to March 2016 (from provinces Semnan, Zanjan and Markazi in Iran) by hospital's medical staff and transferred in viral transport media at $4{ }^{\circ} \mathrm{C}$ to The Influenza and other Respiratory Viruses De-

Tab. 1. HPIV1-4 primers sequences and characteristics.

\begin{tabular}{|c|c|c|c|c|}
\hline Virus & Primer & Sequence & Product Size & Position on $\mathrm{HN}_{\mathrm{c}}$ gene \\
\hline \multirow{2}{*}{ HPIV $_{\mathrm{a}} 1$ (Accession number:AF457102.1) } & forward primer & 5'-AGG AAT TGG CTC AGA TAT GC-3' & \multirow{2}{*}{149 bp } & $451-470$ \\
\hline & reverse primer & $5^{\prime}$-ACT TGG TCC AGG TAA TAA TGA G-3' & & $578-599$ \\
\hline \multirow{2}{*}{ HPIV2 (Accession number:X57559.1) } & forward primer & $5^{\prime}$-GGA TAA TAC AAC AAT CTG CTG-3' & \multirow{2}{*}{337 bp } & $786-806$ \\
\hline & reverse primer & 5'-ATG AGA CCA CCA TAT ACA GG-3' & & $1103-1122$ \\
\hline \multirow{2}{*}{ HPIV3 (Accession number:AB012132.1) } & forward primer & 5'-TAA TAT GAC AGA TGA YAC AAT GC-3' & \multirow{2}{*}{$484 \mathrm{bp}$} & $1005-1024$ \\
\hline & reverse primer & 5'-YGG GTA TGG AGG TCT TGA AC-3' & & $1466-1485$ \\
\hline \multirow{2}{*}{ HPIV4 (Accession number:AB543336.1) } & forward primer & 5'-TCA AAC CCA TTG GTG TTA TAC-3' $^{\prime}$ & \multirow{2}{*}{$558 \mathrm{bp}$} & $546-566$ \\
\hline & reverse primer & $5^{\prime}$-CTC CCT GAG AAG TAA GTT ATT G-3' & & $1082-1103$ \\
\hline
\end{tabular}

$\mathrm{a}$ - human parainfluenza virus, $\mathrm{b}$ - base pair, $\mathrm{c}$ - hemagglutinin neuraminidase 


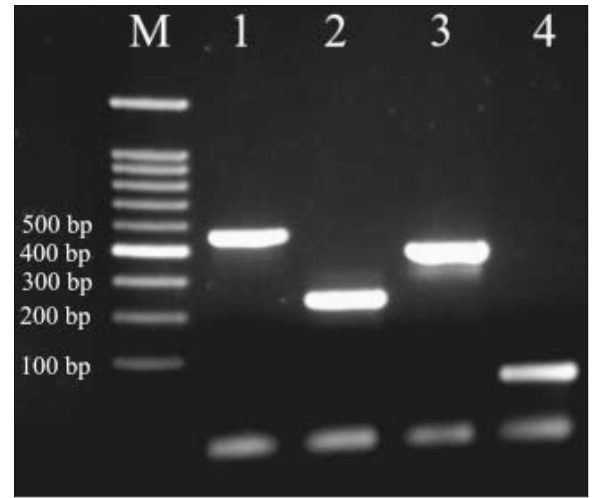

Fig. 1. Results of singleplex PCR reactions with designed primers and their related plasmid template. Lane M, Marker; Lane 1, HPIV4(Positive control(PC)); Lane 2, HPIV-2(PC); Lane 3, HPIV-3(PC); Lane 4, HPIV-1(PC).

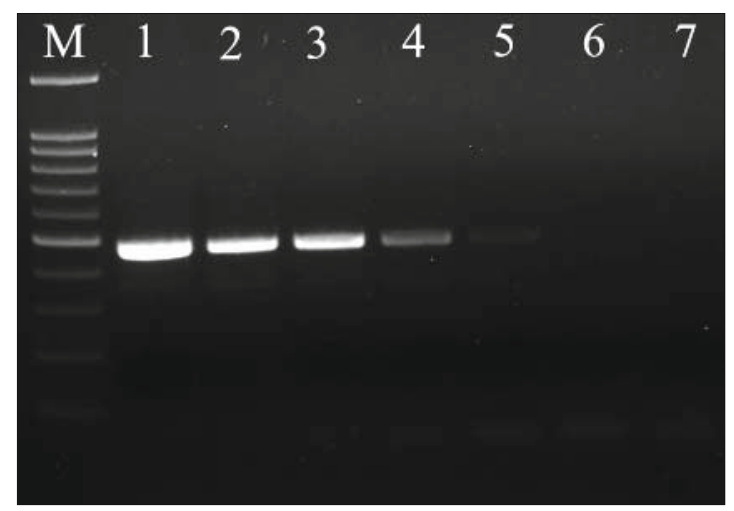

Fig. 2. Results of singleplex PCR reactions on different concentrations of HPIV-3 positive control with related primer pair. Lane M, Marker; Lane 1 to Lane $7,10^{\wedge}-1 \mathrm{ng} / \mathrm{microl}{ }^{\wedge} 0^{\wedge}-6$ of linearized plasmid template, respectively.

partment, Pasteur Institute of Iran, Tehran and were prepared and stored at $-70{ }^{\circ} \mathrm{C}$.

The samples were chosen from influenza negative specimens (tested previously following WHO protocol).

Viral RNA was extracted from patient samples and multiplex RT-PCR was performed on each sample using designed primers to detect HPIVs 1-4 in a single tube.

\section{Results}

\section{Plasmid control}

Singleplex PCR reactions, using designed primers, and plasmids (containing HPIV types 1-4 HN gene) were performed. Each PCR reaction produced a product with desired band size on gel electrophoresis. No other band other than predicted product was observed (Fig. 1).

\section{PCR specificity and sensitivity}

The results of PCR reactions, each containing one primer pair and 3 unrelated templates, showed no band in gel electrophoresis, which proved that the designed primers were indeed type-specific.

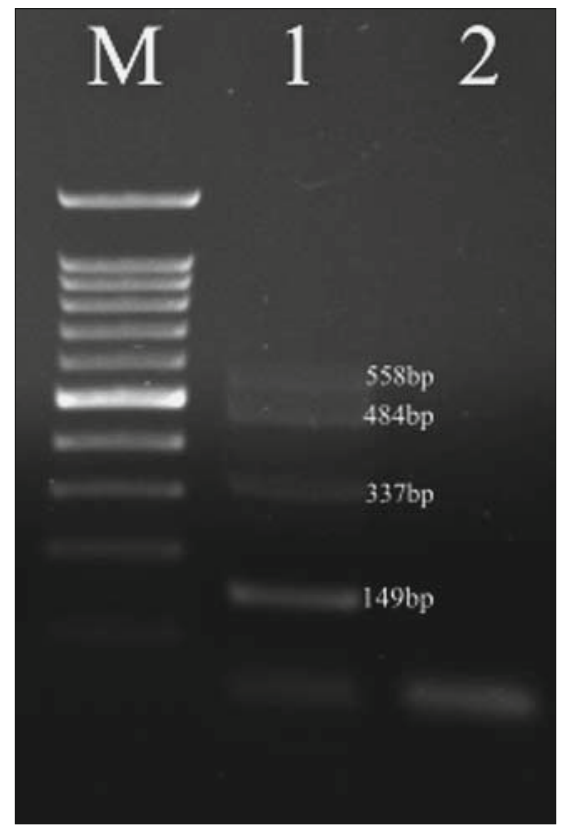

Fig. 3. Result of multiplex PCR on all 4 types of HPIVs plasmids and all four types of primer pairs. Lane M, Marker; Lane 1, HPIV-1, 2, 3 and 4 positive controls; Lane 2, negative control.



Fig. 4. Result of multiplex and monoplex RT-PCR on viral panel nucleic acid. Lane M, Marker; Lane 1, result of multiplex RT-PCR, showing HPIV1, 2 and 3 fragments; Lane 2, Negative control; Lane 3-5, results of monoplex RT-PCR on viral panel using HPIV3, HPIV2 and HPIV1 specific primers, respectively.

To obtain the minimum concentration of plasmid template, PCR reactions with different concentrations of each linearized plasmid and type-specific primers were performed. The least concentration, in which a visible band in gel electrophoresis could be seen, was considered as the limit of detection. For instance, the result for HPIV-3 is shown in Figure 2. The limit of detection was $20,4.4 \times 10^{3}, 5.4 \times 10^{3}$ and $5.3 \times 10^{3}$ plasmid copies for type 1 , type 2, types 3 and type 4, respectively (Fig. 2).

\section{Multiplex PCR}

In a single-tube PCR reaction, containing all 4 primer pairs with their respective plasmid templates, the set up multiplex-PCR ability in simultaneous recognition of HPIV1-4 was confirmed 


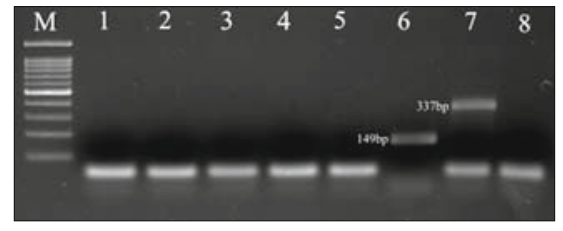

Fig. 5. Results of multiplex RT-PCR on clinical samples. Lane M, Marker; Lane 1 to 5, HPIV1-4 negative; Lane 6, HPIV-1 positive; Lane 7, HPIV-2 positive; Lane 8 HPIV1-4 negative.



Fig. 6. All HPIVs detected in children younger than 5, during 20132016.

by observing 4 separate bands with expected sizes in gel electrophoresis (Fig. 3).

\section{RT-PCR specificity}

A series of monoplex and multiplex RT-PCR assays were performed on a viral panel, containing 10 respiratory viruses including HPIV1-3. In a multiplex RT-PCR assay, three different fragments related to HPIV1-3 (149, 337 and 484 bp, respectively) were observed. In monoplex tests, one type-specific primer pair was used in each reaction and desired bands were observed. The result confirmed that in-house RT-PCR could detect HPIVs in the presence of various viral RNA (Fig. 4).

\section{Detection of HPIVs in clinical samples}

Multiplex RT-PCR was performed on 100 inpatient samples. Nine out of 100 tested samples $(9 \%)$ were positive for the nucleic acid of one type of HPIVs, four HPIV1 and five HPIV2 (Fig. 5). Seasonal distribution of these HPIV-positive samples is shown in Figure 6.

\section{Discussion}

Respiratory infections are one of the major health challenges around the world. These infections can cause a wide range of problems from minor symptoms to fatal diseases $(17,18)$. They are usually more serious and life-threatening in pediatric, geriatric population and patients with cardiac, respiratory, renal and immune deficiency diseases. According to WHO, these infections lead to death of 4 million children annually (19). The causative agents of $80 \%$ of these infections are viruses. One of the important viruses that cause respiratory infections is HPIV, which is the second most common cause of these infections in children under 5 years old, after respiratory syncytial virus. Bronchiolitis, croup and pneumonia caused by HPIV has costed the USA health care system about 259 million dollars each year from 1991 to 2010 (1).

HPIVs can be transmitted through direct and indirect contact with infected discharges and respiratory droplets. Different factors such as: humidity, air flow rate, etc. have been proposed to be involved in transmission of the disease and seasonal pattern of its outbreaks (20), which shows the importance of health care planning in disease prevention in areas with a higher risk of outbreaks and antibiotic management, in case of outbreak (21).

Data about the efficacy of antiviral treatments against HPIVs are limited and contradictory. Ribavirin is proposed to be effective in transplant patients in one study, while negative results were seen in other studies. Although it is used to treat severe HPIV infections in transplant patients, no strong data exists on its benefit (11). On the other hand, efforts to develop a vaccine for these infections have not been successful (2). So, early and accurate diagnosis of the viral infection should still be the top priority of the health care system in order to prevent secondary bacterial infection, which increases morbidity and mortality and unnecessary use of antibiotics (18).

Radiographic methods are inefficient in diagnosing viral infections, as they cannot differentiate between different viruses, and even are unable to diagnose viral infections from bacterial ones. Considering the shortcomings of clinical methods, laboratory tests are needed. Different laboratory assays such as serological methods (including immunofluorescence and IgG measurement), viral culture, and molecular methods have been used. Every method has its advantages and disadvantages, but molecular methods like RT-PCR and real-time RT-PCR have been shown to have high efficiency and precision, are more rapid in virus detection -even in low viral loads-, and are able to determine the viral types and subtypes. Comparing to the other methods, nucleic acid based techniques cost less when used in large scales (16, 21-24).

It should be emphasized that the presence of viral RNA in patient sample alone can not prove that the present virus is the cause of the infection. Therefore, samples from patients. who present respiratory infection symptoms, should be evaluated for the presence of all common respiratory viruses, which suggests the use of multiplex methods. By using multiplex RT-PCR, fast, affordable, precise and definitive diagnosis can be achieved (10).

Real-time RT-PCR has been suggested by some studies to be more sensitive than RT-PCR, but conventional RT-PCR costs less and is more available for large-scale use as a regular test for diagnosing viral respiratory infections (18).

In consideration of all above-mentioned factors, a multiplex RT-PCR assay was chosen to be set up as a diagnostic test for recognizing all 4 types of HPIV in a single-tube reaction in nasopharyngeal samples.

Genes for HN, phosphoprotein, fusion protein, and nucleoprotein have been used as target genes for primer design in order to simulta- 
neously identify HPIVs with RT-PCR (3, 25-27). Among all 4 types ofHPIV, HN gene has the most genetic and antigenic differences (6), which makes it a very suitable choice in primer designing and was used as the target gene for the primers in present study. In addition, in a multiplex reaction, melting temperature of each primer, PCR product size, the final concentration of each primer, and other components of PCR should be considered to ensure yielding all desired products in the reaction (28). Taking all steps necessary to eliminate inhibitors and impurities in samples and avoiding contamination (especially in presence of plasmids) in the PCR process is crucial.

Although the set in-house multiplex RT-PCR was able to detect the nucleic acid of HPIV types in viral panel and clinical samples, the number of samples was not enough to draw a conclusion about the epidemiology and seasonal pattern of HPIVs. However, the most positive samples in our study were collected during winter (more than 44 percent of total positive samples).

In conclusion, the present study shows that the designed multiplex RT-PCR could detect HPIVs nucleic acid in clinical samples, which makes it an option for rapid and precise detection of HPIVs with a low cost in a larger scale and as a standard assay for diagnosis in health care protocols.

\section{References}

1. Abedi GR, Prill MM, Langley GE et al. Estimates of Parainfluenza VirusAssociated Hospitalizations and Cost Among Children Aged Less Than 5 Years in the United States, 1998-2010. J Pediatric Infect Dis Soc 2016; 5 (1): 7-13.

2. Pecchini R, Berezin EN, Souza MC et al. Parainfluenza virus as a cause of acute respiratory infection in hospitalized children. Braz J Infect Dis 2015; 19 (4): 358-362.

3. Indumathi C, Gunanasekaran P, Kaveri K et al. Isolation \& molecular characterization of human parainfluenza virus in Chennai, India. Indian J Med Res 2015; 142 (5): 583.

4. Villaran MV, Garcia J, Gomez $\mathbf{J}$ et al. Human parainfluenza virus in patients with influenza-like illness from Central and South America during 2006-2010. Influenza Other Respir Viruses 2014; 8 (2): 217-227.

5. Aguilar JC, Perez-Brena MP, Garcia ML, Cruz N, Erdman DD, Echevarria JE. Detection and identification of human parainfluenza viruses 1 , 2,3 , and 4 in clinical samples of pediatric patients by multiplex reverse transcription-PCR. J Clin Microbiol 2000; 38 (3): 1191-1195.

6. Mao N, Ji Y, Xie Z et al. Human parainfluenza virus-associated respiratory tract infection among children and genetic analysis of HPIV-3 strains in Beijing, China. PLoS One 2012; 7 (8): e43893.

7. Fry AM, Curns AT, Harbour K, Hutwagner L, Holman RC, Anderson LJ. Seasonal trends of human parainfluenza viral infections: United States, 1990-2004. Clin Infect Dis 2006; 43 (8): 1016-1022.

8. Weinberg GA. Parainfluenza viruses: an underappreciated cause of pediatric respiratory morbidity. J Pediatric Infect Dis Soc 2006; 25 (5): 447-448.

9. Seo S, Xie H, Campbell AP et al. Parainfluenza virus lower respiratory tract disease after hematopoietic cell transplantation: viral detection in the lung predicts outcome. Clin Infect Dis 2014; 58 (10): 1357-1368.

10. Falsey AR, Becker KL, Swinburne AJ et al. Bacterial complications of respiratory tract viral illness: a comprehensive evaluation. J Infect Dis 2013; 208 (3): 432-441.

11. Park SY, Baek S, Lee SO et al. Efficacy of oral ribavirin in hematologic disease patients with paramyxovirus infection: analytic strategy using propensity scores. Antimicrob Agents Chemother 2013; 57 (2): 983-989.
12. Senchi K, Matsunaga S, Hasegawa H, Kimura H, Ryo A. Development of oligomannose-coated liposome-based nasal vaccine against human parainfluenza virus type 3. Front Microbiol 2013; 4: 346.

13. Englund JA, Karron RA, Cunningham CK et al. Safety and infectivity of two doses of live-attenuated recombinant cold-passaged human parainfluenza type 3 virus vaccine rHPIV3cp45 in HPIV3-seronegative young children. Vaccine 2013; 31 (48): 5706-5712.

14. Schmidt AC, Schaap-Nutt A, Bartlett EJ et al. Progress in the development of human parainfluenza virus vaccines. Expert Rev Respir Med 2011; 5 (4): 515-526.

15. Henrickson KJ. Parainfluenza viruses. Clin Microbiol Rev 2003; 16 (2): 242-264.

16. Bouvet D, Gaudy-Graffin C, Garot D, Sunder S, De Gialluly C, Goudeau A. Diagnosis of community-acquired acute respiratory illness: From conventional microbiological methods to molecular detection (multiplex). Pathol Biol 2015; 63 (2): 69-73.

17. de-Paris F, Beck C, Pires MR, dos Santos RP, Kuchenbecker Rde S, Barth AL. Viral epidemiology of respiratory infections among children at a tertiary hospital in Southern Brazil. Rev Soc Bras Med Trop 2014; 47 (2): 223-226.

18. Choudhary ML, Anand SP, Heydari M et al. Development of a multiplex one step RT-PCR that detects eighteen respiratory viruses in clinical specimens and comparison with real time RT-PCR. J Virol Methods 2013; 189 (1): $15-19$.

19. Hong H-L, Hong S-B, Ko G-B et al. Viral infection is not uncommon in adult patients with severe hospital-acquired pneumonia. PloS One 2014; 9 (4): e95865.

20. Burke CW. Mode of Parainfluenza Virus Transmission Determines the Dynamics of Primary Infection and Protection from Reinfection. PLoS Pathog 2013; 9 (11): e1003786.

21. Templeton KE, Scheltinga SA, van den Eeden WC, Graffelman AW, van den Broek PJ, Claas EC. Improved diagnosis of the etiology of community-acquired pneumonia with real-time polymerase chain reaction. Clin Infect Dis 2005; 41 (3): 345-351.

22. Arango AE, Jaramillo S, Perez $\mathbf{J}$ et al. Influenza-like illness sentinel surveillance in one hospital in Medellin, Colombia 2007-2012. Influenza Other Respir Viruses 2015; 9 (1): 1-13.

23. Falsey AR, McElhaney JE, Beran J et al. Respiratory Syncytial Virus and Other Respiratory Viral Infections in Older Adults With Moderate to Severe Influenza-like Illness. J Infect Dis 2014; 209 (12): 1873-1881.

24. Mahony JB, Blackhouse G, Babwah J et al. Cost analysis of multiplex PCR testing for diagnosing respiratory virus infections. J Clin Microbiol 2009; 47 (9): 2812-2817.

25. Li H, Wei Q, Tan A, Wang L. Epidemiological analysis of respiratory viral etiology for influenza-like illness during 2010 in Zhuhai, China. Virol J 2013; 10: 143.

26. Karron RA, Froehlich JL, Bobo L, Belshe RB, Yolken RH. Rapid detection of parainfluenza virus type 3 RNA in respiratory specimens: use of reverse transcription-PCR-enzyme immunoassay. J Clin Microbiol 1994; 32 (2): 484-488.

27. Fan J, Henrickson KJ. Rapid diagnosis of human parainfluenza virus type 1 infection by quantitative reverse transcription-PCR-enzyme hybridization assay. J Clin Microbiol 1996; 34 (8): 1914-1917.

28. Elnifro EM, Ashshi AM, Cooper RJ, Klapper PE. Multiplex PCR: optimization and application in diagnostic virology. Clin Microbiol Rev 2000; 13 (4): 559-570.

Received February 15, 2017. Accepted June 26, 2017. 